\title{
Studies of Tumbling Motion Generated During Intake in a Bowl-in-Piston Engine
}

Wen-Cheng Huang

Professor, Department of Harbor and River Eng., National Taiwan Ocean Univ., Keelung 20224, Taiwan, Republic of China

Follow this and additional works at: https://jmstt.ntou.edu.tw/journal

Part of the Civil and Environmental Engineering Commons

\section{Recommended Citation}

Huang, Wen-Cheng (2009) "Studies of Tumbling Motion Generated During Intake in a Bowl-in-Piston Engine," Journal of Marine Science and Technology. Vol. 7: Iss. 1, Article 8.

DOI: $10.51400 / 2709-6998.2513$

Available at: https://jmstt.ntou.edu.tw/journal/vol7/iss1/8

This Research Article is brought to you for free and open access by Journal of Marine Science and Technology. It has been accepted for inclusion in Journal of Marine Science and Technology by an authorized editor of Journal of Marine Science and Technology. 


\title{
KALMAN FILTER EFFECTIVE TO HYDROLOGIC ROUTING?
}

\author{
Wen-Cheng Huang*
}

Keywords: Flood, Flood Routing, Missile, Anti-missile, Kalman filter.

\begin{abstract}
Approaching flood can be likened to a oncoming missile, and flood routing is viewed as to build an anti-missile system. The applications of the Kalman filter to hydrologic models are not suitable. The Kalman filter fails to yield totally effective predictions in the hydrologic routing by the fact that any specific objective (peakflow) cannot be designated in advance. Without predetermined objectives, the predicted flows cannot catch the real values but follow the traces of the real hydrograph.
\end{abstract}

\section{INTRODUCTION}

Estimation is the procedure of determining the state of a system from noisy measurements, taking account of measurement errors and system disturbances. The estimation method developed by Kalman (1960) would be the most common. One of the most substantial characteristics of the Kalman filter is its recursive procedure that processes measurements to obtain the optimal estimate. Kalman filter problems appear naturally in many physical circumstances where an estimation theory is needed to sequentially process measurements. It has been applied to a broad range of fields, such as navigation system control, power system control and so on. Its use in hydrology began in 1973, when Hino applied the Kalman filter to identify the parameters of a linear, lumped, discharge model from serial observations, then use the new parameters updated by new observations to forecast streamflow. Thereafter interest and enthusiasm arose to explore the applications of the Kalman filter to hydrology. Numerous papers and reports have been issued. The work can be found in Chiu (1978) and Wood (1980).

While the Kalman filtering theory provides a di-

Paper Received June 7, 1999. Revised June 25, 1999. Accepted June 27, 1999. Author for Correspondence: Wen-Cheng Huang.

*Professor, Department of Harbor and River Eng., National Taiwan Ocean Univ., Keelung 20224, Taiwan, Republic of China. rection of study to hydrology, we must ask: Is it really unmistakable? The objective of this paper is to examine the applicability of the Kalman filter to hydrologic routing. In this study, two examples related to a falling body similar to an approaching flood, and a hydrologic model with unit hydrograph will be examined by using the Kalman filter.

\section{INTERPRETATIONS}

In a discrete form, the discrete Kalman filter equations for deterministic input are

$$
\begin{aligned}
X(k+1)= & \Phi(k+1, k) X(k)+U(k)+W(k+1) \\
& W(k+1) \sim N(0, Q(k+1)) \\
Y(k+1)= & H(k+1) X(k+1)+V(k+1) \\
& V(k+1) \sim N(0, R(k+1))
\end{aligned}
$$

where

$X(k) \quad:$ state vector at time $k$

$\Phi(k+1, k)$ : state transition matrix from time $k$ to $k+1$

$U(k) \quad:$ deterministic input

$Y(k+1) \quad:$ measurement at time $k+1$

$H(k+1) \quad:$ measurement matrix

$Q(k+1) \quad$ : system noise covariance matrix

$R(k+1) \quad$ : measurement noise covariance matrix

Assume that $H(k+1)=0$, then the measurement contains no information about the state. On the other hand, suppose that $\Phi(k+1, k)=0$, so that the system is a memoryless form. The notation of filter variables mentioned above will be found in many books on Kalman filtering theory (e.g., Jazwinski 1970; Gelb 1974; Bozic 1979). Given the assumption that a linear form exists between the updated state estimate and the measurement, the optimal filter equations which minimize the estimation error can thus be derived, such as error covariance matrix $P(k)$ and Kalman gain matrix $K(k)$. The computation corresponding to a sequence of observations for prediction of $X(k+1 \mid k), P(k+1 \mid k)$ and updating of $X(k$ $+1 \mid k+1), P(k+1 \mid k+1), K(k+1)$ will be performed 
recursively. That is,

$$
\begin{aligned}
& X(k+1 \mid k)=\Phi(k+1, k) X(k \mid k)+U(k) \\
& \begin{aligned}
P(k+1 \mid k)= & \Phi(k+1, k) P(k \mid k) \Phi^{T}(k+1, k) \\
& +Q(k+1)
\end{aligned} \\
& \begin{aligned}
X(k+1 \mid k+1) & =X(k+1 \mid \mathrm{k})+K(k+1)[Y(k+1) \\
& -H(k+1) X(k+1 \mid k)]
\end{aligned} \\
& P(k+1 \mid k+1)=[I-K(k+1) H(k+1)] P(k+1 \mid k)
\end{aligned}
$$

$$
\begin{aligned}
K(k+1) & =P(k+1 \mid k) H^{T}(k)[H(\mathrm{k}+1) P(k \\
& \left.+1 \mid k) H^{T}(k+1)+R(k+1)\right]^{-1}
\end{aligned}
$$

where superscript $T$ denotes the transpose of a matrix and

$X(k+1 \mid k) \quad:$ state prediction

$X(k+1 \mid k+1):$ state estimate update

$P(k+1 \mid k) \quad$ : error covariance prediction matrix

$P(k+1 \mid k+1)$ : error covariance update matrix

$K(k+1) \quad$ : Kalman gain matrix

Since complete information of the physical process is usually not available, the difference exists between the true model and the used model, such that the model error can not be avoided. It is inevitable that an untrue model will downgrade the filter performance, and model divergence may arise. Therefore, the error sensitivity analysis of the filter model is vital (Jazwinski 1970; Gelb 1974).

\section{EXAMPLES}

Hydrologic events have a great deal of irregular and uncertain phenomena. As knowledge on hydrologic behavior grows, hydrologic models are subsequently upgraded. Sometimes hydrologic models are simplified to approximate a real situation due to nonlinearity. In this study, in order to diagnose the applicability of the Kalman filtering to hydrologic estimation, unit hydrograph indicating the rainfall-runoff relationship will be illustrated. However, a real transition matrix and deterministic inputs contained in a hydrologic system model are seldom precisely known. Therefore, an analogous example will be explained firstly, in order to survey the effect of the model error. That is, a noisefree system (i.e., $Q(k)=0$ ) representing a falling body in a constant field is applied (Jazwinski 1970, pp. 287292; Bozic 1979, pp. 130-133).

\section{Case 1: Falling Body}

In this example, the actual system model is given as

$$
\left[\begin{array}{l}
x_{1}(k+1) \\
x_{2}(k+1)
\end{array}\right]=\left[\begin{array}{cc}
1 & 1 \\
0 & 1
\end{array}\right]\left[\begin{array}{l}
x_{1}(k) \\
x_{2}(k)
\end{array}\right]+\left[\begin{array}{l}
-0.5 g \\
-1.0 g
\end{array}\right]
$$

with the real state transition matrix

$$
\Phi(k+1, k)=\left[\begin{array}{ll}
1 & 1 \\
0 & 1
\end{array}\right]
$$

The measurement model is written as

$$
y(k)=\left[\begin{array}{ll}
1 & 0
\end{array}\right]\left[\begin{array}{l}
x_{1}(k) \\
x_{2}(k)
\end{array}\right]+V(k)
$$

where $x_{1}(k)$ and $x_{2}(k)$ denote the position and velocity individually, and the measurement noise is given by $R(k)=1$.

Before starting the estimation, the true initial conditions of $x_{1}(0)=100, x_{2}(0)=0$ and $g=1$ are assumed. Moreover, the initial values of the state vector and the error covariance matrix are also assumed to be

$$
X(0 \mid 0)=\left[\begin{array}{c}
95 \\
1
\end{array}\right] P(0 \mid 0)=\left[\begin{array}{cc}
10 & 0 \\
0 & 1
\end{array}\right]
$$

Notice that the solution of this example outlined in Jazwinski (1970) and Bozic (1979) are computed only for $t=1,2, \ldots, 6$, where the real filter model is operated. However, what would the result be if incorrect information is imposed on the model? Therefore, emphasis here is placed on the error sensitivity analysis. Also, detailed computations will be demonstrated for $t$ $=1,2, \ldots, 14$, where the observations after $t=6$ are assumed by the author. The results of the true trajectory and the filter performance with real system are shown in Table 1. We see that the error covariances of position and velocity decrease, and the updated errors are smaller than the predicted errors due to measurement involved. We also observe that the Kalman gain becomes smaller, indicating that further measurements provide less information for sufficiently large $t$.

Special cases using incorrect values of $\Phi, H, Q$, $R$ or $P(0 \mid 0)$ have been studied by some authors (e.g., Fagin 1964; Heffes 1966). Consider here the case of error in alone. Suppose that we are not familiar with the system model of a falling body. The erroneous model, for example, has the transition matrix as

$$
\Phi(k+1, k)=\left[\begin{array}{cc}
1 & 10 \\
0 & 1
\end{array}\right]
$$

The model error can be viewed as an error in $\Phi$. The filtering results with incorrect transition matrix are summarized in Table 2. As we see, the filter diverges. The position prediction clearly gets lost, and the predicted position error does not decrease. In spite of the fact that the position error can drop dramatically by measuring the falling body (the Kalman gain of position 
Table 1. Falling body in a constant field with true state transition matrix

\begin{tabular}{|c|c|c|c|c|c|c|c|c|c|c|c|c|c|}
\hline$k$ & $x_{1}(k)$ & $x_{2}(k)$ & $y(k)$ & $x_{1}(k \mid k-1)$ & $x_{2}(k \mid k-1)$ & $P_{11}(k \mid k-1)$ & $P_{22}(k \mid k-1)$ & $x_{1}(k \mid k)$ & $x_{2}(k \mid k)$ & $P_{11}(k \mid k)$ & $P_{22}(k \mid k)$ & $K_{1}(k)$ & $K_{2}(k)$ \\
\hline 0 & 100.0 & .0 & & & & & 95.00 & 1.00 & 10.00 & 1.00 & & & \\
\hline 1 & 99.5 & -1.0 & 100.0 & 95.50 & .00 & 11.00 & 1.00 & 99.63 & .38 & .92 & .92 & .92 & .08 \\
\hline 2 & 98.0 & -2.0 & 97.9 & 99.50 & -.63 & 2.00 & .92 & 98.43 & -1.16 & .67 & .58 & .67 & .33 \\
\hline 3 & 95.5 & -3.0 & 94.4 & 96.78 & -2.16 & 1.92 & .58 & 95.21 & -2.90 & .66 & .30 & .66 & .31 \\
\hline 4 & 92.0 & -4.0 & 92.7 & 91.81 & -3.90 & 1.58 & .30 & 92.35 & -3.69 & .61 & .15 & .61 & .24 \\
\hline 5 & 87.5 & -5.0 & 87.3 & 88.16 & -4.69 & 1.24 & .15 & 87.68 & -4.84 & .55 & .08 & .55 & .17 \\
\hline 6 & 82.0 & -6.0 & 82.1 & 82.34 & -5.84 & .98 & .08 & 82.22 & -5.87 & .50 & .05 & .50 & .13 \\
\hline 7 & 75.5 & -7.0 & 75.4 & 75.85 & -6.87 & .81 & .05 & 75.65 & -6.92 & .45 & .03 & .45 & .10 \\
\hline 8 & 68.0 & -8.0 & 68.8 & 68.23 & -7.92 & .68 & .03 & 68.46 & -7.87 & .40 & .02 & .40 & .08 \\
\hline 9 & 59.5 & -9.0 & 59.0 & 60.08 & -8.87 & .58 & .02 & 59.68 & -8.94 & .37 & .02 & .37 & .06 \\
\hline 10 & 50.0 & -10.0 & 50.6 & 50.24 & -9.94 & .51 & .02 & 50.36 & -9.92 & .34 & .01 & .34 & .05 \\
\hline 11 & 39.5 & -11.0 & 39.4 & 39.94 & -10.92 & .46 & .01 & 39.77 & -10.95 & .31 & .01 & .31 & .04 \\
\hline 12 & 28.0 & -12.0 & 28.3 & 28.32 & -11.95 & .41 & .01 & 28.31 & -11.95 & .29 & .01 & .29 & .04 \\
\hline 13 & 15.5 & -13.0 & 14.5 & 15.87 & -12.95 & .37 & .01 & 15.50 & -12.99 & .27 & .01 & .27 & .03 \\
\hline 14 & 2.0 & -14.0 & 2.1 & 2.00 & -13.99 & .34 & .01 & 2.03 & -13.99 & .25 & .00 & .25 & .03 \\
\hline
\end{tabular}

$x_{i}(k)$ : true values; $i=1$ (position), $i=2$ (velocity); $y(k)$ : position observations

$x_{i}(k \mid k-1)$ : predicted state; $x_{i}(k \mid k)$ : updated state; $K_{i}(k)$ : Kalman gain

$P_{i i}(k \mid k-1)$ : predicted error variance; $P_{i i}(k \mid k)$ : updated error variance

goes to one), the addition of a measurement model improves the estimate just to a certain degree, and without any effective way. That is, the filtering to position prediction seems not to appear prominent on account of the incorrect model.

\section{Case 2: Flood Routing}

In problems of hydrologic routing, for example, the Muskingum model might be one of the most commonly used hydrologic models. The model is described by

$$
O_{k+1}=C_{0} I_{k+1}+C_{1} I_{k}+C_{2} O_{k}
$$

where

$O_{k} \quad:$ streamflow in the under reach at time $k$

$I_{k} \quad:$ streamflow in the upper reach at time $k$

$C_{0}, C_{1}, C_{2}$ : model's parameters, and $C_{0}+C_{1}+C_{2}=$ 1.0

In applying the linear Kalman filter to the Muskingum model, Wang et al. (1987) described this system by,

$\left[\begin{array}{c}O_{k+1} \\ O_{k}\end{array}\right]=\left[\begin{array}{cc}C_{2} & 0 \\ 1 & 0\end{array}\right]\left[\begin{array}{c}O_{k} \\ O_{k-1}\end{array}\right]+\left[\begin{array}{cc}C_{0} & C_{1} \\ 1 & 0\end{array}\right]\left[\begin{array}{c}I_{k+1} \\ I_{k}\end{array}\right]+\left[\begin{array}{c}W_{k+1} \\ 0\end{array}\right]$

for the system model with the state transition matrix

$$
\Phi(k+1, k)=\left[\begin{array}{cc}
C_{2} & 0 \\
1 & 0
\end{array}\right]
$$

and

$$
y(k)=\left[\begin{array}{ll}
1 & 0
\end{array}\right]\left[\begin{array}{c}
O_{k} \\
O_{k-1}
\end{array}\right]+V(k)
$$

for the measurement model, where $y(k)$ represents the observed flows at lower reach. The Muskingum model (Eqs. 13-15) has the similar form as the falling body (Eqs. 8-10). Yet, both of the dimension of state transition matrix is different. The matrix in Eq. 14 has rank one, as compared with rank two of Eq. 9. Thus, the system in Eq. 13 cannot meet the observability condition (Gelb 1974), i.e., the system is not observable. The measurement model in Eq. 15 can do nothing for prediciton model in Eq. 13 but monitor the real-time flood only. The formulation through Eqs.13-15 appears inappropriate.

In another way, as applied by Hino (1973), Eq. 12 is a type of multiple linear equation, and the parameters can be estimated by using the Kalman filtering algorithm. That is,

$$
\left[\begin{array}{l}
C_{0} \\
C_{1} \\
C_{2}
\end{array}\right]_{k+1}=\left[\begin{array}{l}
C_{0} \\
C_{1} \\
C_{2}
\end{array}\right]_{k}+W_{k+1}
$$

and

$$
y(k)=\left[\begin{array}{lll}
I_{k} & I_{k-1} & O_{k-1}
\end{array}\right]\left[\begin{array}{l}
C_{0} \\
C_{1} \\
C_{2}
\end{array}\right]+V(k)
$$

where the state transition matrix in Eq. 16 is an identity matrix. Since the uncertain circumstances in the hydrological conditions during typhoons warrant the subse- 
Table 2. Falling body in a constant field with untrue state transition matrix

\begin{tabular}{|c|c|c|c|c|c|c|c|c|c|c|c|c|c|}
\hline$k$ & $x_{1}(k)$ & $x_{2}(k)$ & $y(k)$ & $x_{1}(k \mid k-1)$ & $x_{2}(k \mid k-1)$ & $P_{11}(k \mid k-1)$ & $P_{22}(k \mid k-1)$ & $x_{1}(k \mid k)$ & $x_{2}(k \mid k)$ & $P_{11}(k \mid k)$ & $P_{22}(k \mid k)$ & $K_{1}(k)$ & $K_{2}(k)$ \\
\hline 0 & 100.0 & .0 & & & & & & 95.00 & 1.00 & 10.00 & 1.00 & & \\
\hline 1 & 99.5 & -1.0 & 100.0 & 104.50 & .00 & 371.00 & 1.00 & 100.01 & -.23 & 1.00 & .03 & 1.00 & .05 \\
\hline 2 & 98.0 & -2.0 & 97.9 & 97.21 & -1.23 & 92.22 & .03 & 97.89 & -1.23 & .99 & .03 & .99 & .01 \\
\hline 3 & 95.5 & -3.0 & 94.4 & 85.14 & -2.23 & 80.74 & .03 & 94.29 & -2.23 & .99 & .03 & .99 & .00 \\
\hline 4 & 92.0 & -4.0 & 92.7 & 71.51 & -3.23 & 81.21 & .03 & 92.44 & -3.23 & .99 & .03 & .99 & .00 \\
\hline 5 & 87.5 & -5.0 & 87.3 & 59.64 & -4.23 & 81.36 & .03 & 86.96 & -4.23 & .99 & .03 & .99 & .00 \\
\hline 6 & 82.0 & -6.0 & 82.1 & 44.16 & -5.23 & 81.36 & .03 & 81.64 & -5.23 & .99 & .03 & .99 & .00 \\
\hline 7 & 75.5 & -7.0 & 75.4 & 28.84 & -6.23 & 81.36 & .03 & 74.83 & -6.23 & .99 & .03 & .99 & .00 \\
\hline 8 & 68.0 & -8.0 & 68.8 & 12.03 & -7.23 & 81.36 & .03 & 68.11 & -7.23 & .99 & .03 & .99 & .00 \\
\hline 9 & 59.5 & -9.0 & 59.0 & -4.69 & -8.23 & 81.36 & .03 & 58.23 & -8.23 & .99 & .03 & .99 & .00 \\
\hline 10 & 50.0 & -10.0 & 50.6 & -24.57 & -9.23 & 81.36 & .03 & 49.69 & -9.23 & .99 & .03 & .99 & .00 \\
\hline 11 & 39.5 & -11.0 & 39.4 & -43.11 & -10.23 & 81.36 & .03 & 38.40 & -10.23 & .99 & .03 & .99 & .00 \\
\hline 12 & 28.0 & -12.0 & 28.3 & -64.40 & -11.23 & 81.36 & .03 & 27.17 & -11.23 & .99 & .03 & .99 & .00 \\
\hline 13 & 15.5 & -13.0 & 14.5 & -85.63 & -12.23 & 81.36 & .03 & 13.28 & -12.23 & .99 & .03 & .99 & .00 \\
\hline 14 & 2.0 & -14.0 & 2.1 & -109.52 & -13.23 & 81.36 & .03 & .74 & -13.23 & .99 & .03 & .99 & .00 \\
\hline
\end{tabular}

$x_{i}(k)$ : true values; $i=1$ (position), $i=2$ (velocity); $y(k)$ : position observations

$x_{i}(k \mid k-1)$ : predicted state; $x_{i}(k \mid k)$ : updated state; $K_{i}(k)$ : Kalman gain

$P_{i i}(k \mid k-1)$ : predicted error variance; $P_{i i}(k \mid k)$ : updated error variance

quent discharges as a nonstationary series, the related parameters inside hydrologic model could be regarded as variables depending upon the change of these circumstances.

In this study, for example, the appropriateness for time-varying parameters of unit hydrograph renewed by the Kalman filtering algorithm is tested. As compared with Eqs. 16-17, the system model and measurement model are as follows.

$$
\left[\begin{array}{c}
U_{1} \\
U_{2} \\
\vdots \\
U_{n}
\end{array}\right]_{k+1}=\left[\begin{array}{c}
U_{1} \\
U_{2} \\
\vdots \\
U_{n}
\end{array}\right]_{k}+W_{k+1}
$$

and

$$
y(k)=\left[\begin{array}{lllll}
I_{k} & I_{k-1} & \cdots & I_{1}
\end{array}\right]\left[\begin{array}{c}
U_{1} \\
U_{2} \\
\vdots \\
U_{k}
\end{array}\right]+V(k)
$$

where $I_{k}$ and $U_{k}$ correspond to the excess rainfall and the value of unit hydrograph at time $k$, respectively. As shown in Table 3, The unit hydrograph of $10 \mathrm{~mm}$ excess rainfall with one hour duration at the Feitsui damsite will be adopted to verify its acceptability. Further, the values in Table 3 are regarded as the initial value of state vector as shown in Eq. 18.

In order to evaluate the performance of the rainfall-runoff model, some criteria are adopted as follows.
Coefficient of Efficiency: $C E=\frac{S_{0}-S_{1}}{S_{0}}$

Mean Square Error: $\quad M S E=\sum_{t=1}^{M} \frac{\left(Y_{t}-F_{t}\right)^{2}}{M}$

Mean Absolute Deviation: $M A D=\sum_{t=1}^{M} \frac{\left|Y_{t}-F_{t}\right|}{M}$

Mean Relative Error:

$$
M R E=\frac{\sum_{t=1}^{M} \frac{Y_{t}-F_{t}}{F_{t}}}{M}
$$

Volume Error:

$$
V E=\frac{\sum_{t=1}^{M} Y_{t}-F_{t}}{\sum_{t=1}^{M} Y_{t}}
$$

Peak Time Error:

$$
P T E=P T\left(Y_{t}\right)-P T\left(F_{t}\right)
$$

Peak Value Error:

$$
P V E=\frac{\operatorname{peak}\left(Y_{t}\right)-\operatorname{peak}\left(F_{t}\right)}{\operatorname{peak}\left(Y_{t}\right)}
$$

in which,

$$
\begin{aligned}
& S_{0}=\sum_{t=1}^{M}\left(Y_{t}-\mu\right)^{2} \\
& S_{1}=\sum_{t=1}^{M}\left(Y_{t}-F_{t}\right)^{2}
\end{aligned}
$$

and

$$
\begin{array}{ll}
Y_{t}: & \text { observed flow } \\
F_{t}: & \text { predicted flow } \\
M: & \text { number of data applied in verification } \\
& \text { period } \\
\mu: & \text { mean value of } Y_{t}
\end{array}
$$


Table 3. Unit Hydrograph of $10 \mathrm{~mm}$ Excess Rainfall with 1-hr Duration at Feitsui Damsite

\begin{tabular}{cc:cc}
\hline hour & discharge $\left(\mathrm{m}^{3} / \mathrm{s}\right)$ & hour & discharge $\left(\mathrm{m}^{3} / \mathrm{s}\right)$ \\
\hline 1 & 12 & 8 & 50 \\
2 & 36 & 9 & 28 \\
3 & 77 & 10 & 14 \\
4 & 149 & 11 & 7 \\
5 & 206 & 12 & 4 \\
6 & 161 & 13 & 2 \\
7 & 92 & 14 & 1 \\
\hline
\end{tabular}

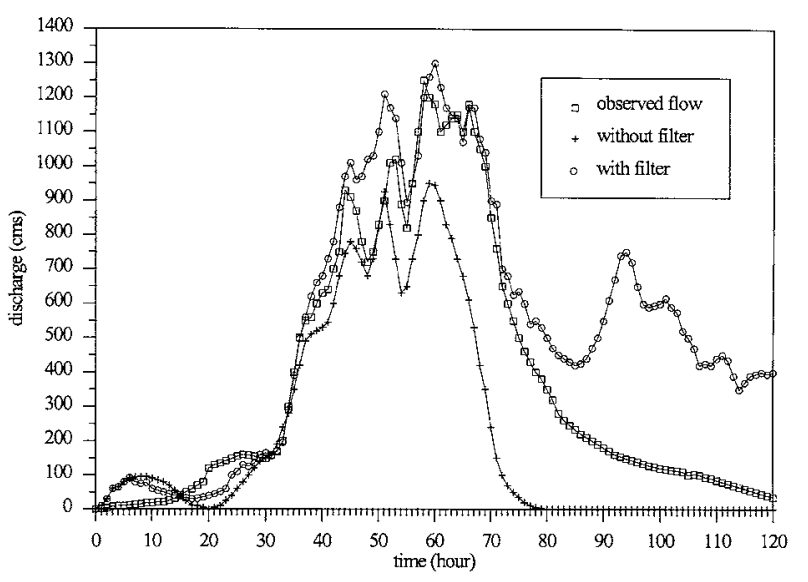

Fig. 1. Rainfall-runoff modeling by unit hydrograph (ORA).

$P T\left(Y_{t}\right): \quad$ occurrence time of observed peakflow $P T\left(F_{t}\right)$ : occurrence time of predicted peakflow $\operatorname{peak}\left(Y_{t}\right)$ : observed peakflow $\operatorname{peak}\left(F_{t}\right)$ : predicted peakflow

Figs. 1-4 present the various hydrographs developed by unit hydrograph with/without the Kalman filter for the selected events (Table 4). Clearly, the hydrographs generated by the type of unit hydrograph without Kalman filter die out quickly. It might imply that fixed unit hydrograph is not appropriate. After applying the Kalman filter technique and changing the related parameters of the unit hydrograph corresponding to the circumstances, the accuracy of flow simulation is obviously improved. During the flood period the most important factor is to know the happening of flow and its volume in advance to avoid probable flood damage. But Table 5 reveals the unfiltered unit hydrograph does not fit well, based upon the related indicators. In contrast, the modified type of unit hydrograph combined with the Kalman filtering technique improves the efficiency of the rainfall-runoff model dramatically, as seen in Table 6. The usefulness of the Kalman filtering technique while facing a nonstationary series of input such as typhoon-borne

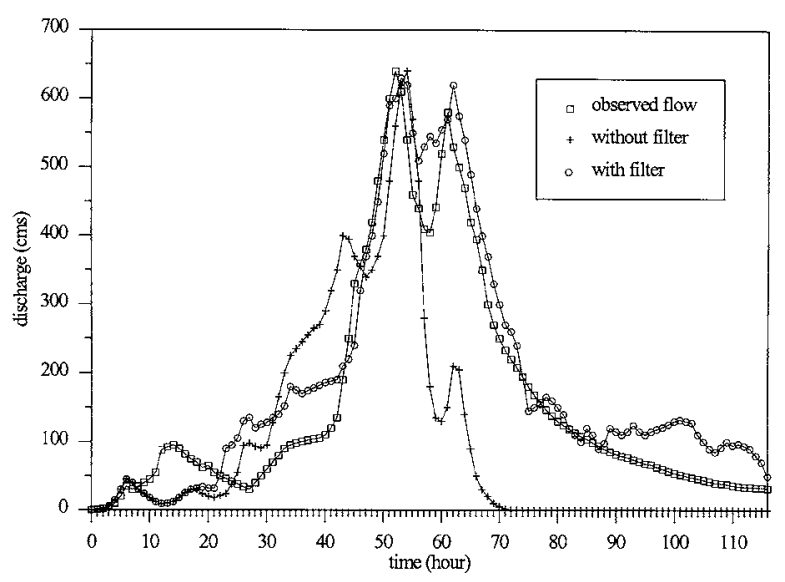

Fig. 2. Rainfall-runoff modeling by unit hydrograph (PERCY).

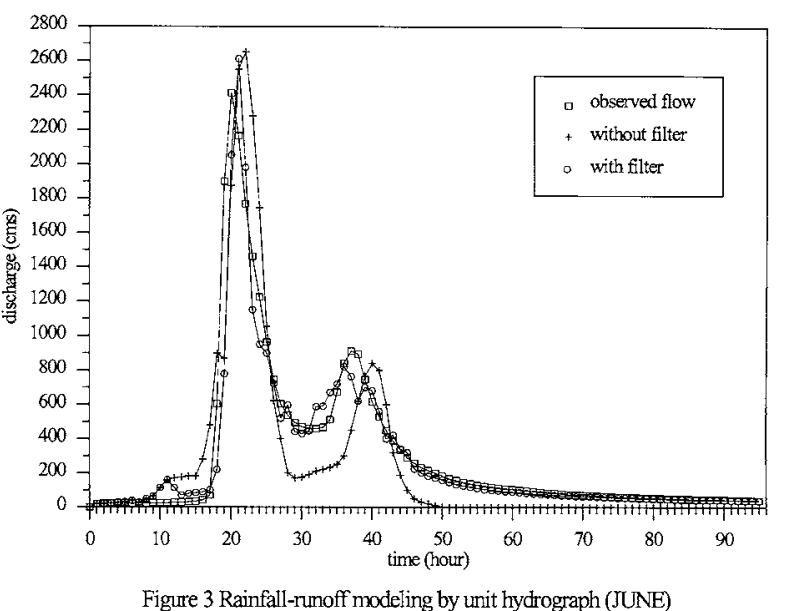

Fig. 3. Rainfall-runoff modeling by unit hydrograph (JUNE).

rainfall seems to be approved. However, is it actually unmistakable?

It is seen that the Kalman filter is excellently applicable to the navigation system while in launching missiles, aircraft and cruisers to reach their targets. In navigation, how to reach an intended target accurately is most critical, and the system model can be adjusted by a Kalman-like filter after starting the filtering process. The cruise missile, for example, is equipped with both an inertial guidance system and a computer and radar to keep up its preprogrammed flight path. Of course, the filter performance will be improved promptly, as the measurement interval is shorter.

In reality, imminent flood can be likened to an oncoming missile, and flood routing is similar to establishing an anti-missile system. The goal aiming to destroy approaching missiles has been likened to 'hitting a bullet with a bullet', a technical challenge as yet unfulfilled. It's still challenging to predict the arrival 


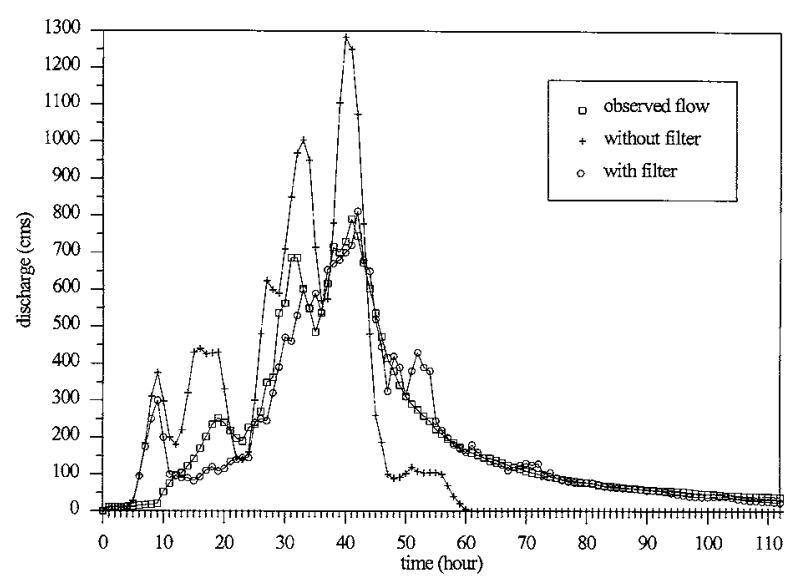

Fig. 4. Rainfall-runoff modeling by unit hydrograph (CLARA).

time and volume of oncoming flood precisely. Similar to the aforementioned example for a falling body, both measurement devices (radar/satellite) for catching a threatening missile and a proper system model for position prediction are needed. Inferior formulation of a system model, such as Eq. 11 or Eq. 13, leads prediction into deficient outcomes. In those cases, the observations cannot upgrade the prediction efficiency but check the real-time position of missile (falling body) or volume of flood only.

In addition, there is an essential distinction between navigation system and hydrology system. The former has given objectives, whereas the latter has not any predetermined objectives within the process. In flood routing, we are considerably anxious about the variation of hydrograph at a specific site, in particular
Table 4. Selected Typhoons for the Rainfall-Runoff Modeling

\begin{tabular}{ll}
\hline typhoon & occurrence \\
\hline ORA & Oct. $11-151978$ \\
PERCY & Sept. $16-201980$ \\
JUNE & June $20-231981$ \\
CLARA & Sept. $20-241981$ \\
\hline
\end{tabular}

the magnitude of the peakflow and its arrival time. The hydraulic method of flood routing can be applied to determine the velocity and the water surface profile along a stream, based on the given hydrograph at an upstream site. In this case, any specific peakflow (objective) which may cause damage to a downstream point could be explored. Based upon a sequence of observations of the upstream point, the velocity of peakflow propagation moving through a channel reach may be detected. Thereafter, the arrival time of the peakflow to the specified downstream point might be predicted in advance. In contrast, flood routing by using hydrologic method cannot visualize any specific peakflow (objective) in advance until it is observed at the downstream site. In this situation, the Kalman filter becomes ineffective in flood prediction during the filtering process. As seen in Table 6, the results seem remarkable, by changing model parameters with the Kalman filter, but the predicted flows still cannot catch the real values but follow the traces of the real hydrograph, as displayed in Figs. 1-4. The predicted time for peakflow usually arrived after a delay of at least one step. Based on the aforementioned interpretation, the application of the Kalman filter to hydrology is

Table 5. Diagnostic Checking of Rainfall-Runoff Model Unit Hydrograph with Constant Parameters

\begin{tabular}{lccccccc}
\hline typhoon & MSE & MAD & MRE & VER & PVE & PTE & CE \\
\hline ORA & 49822.63 & 159.60 & -0.195 & 0.389 & 0.243 & 6 & 0.673 \\
PERCY & 20287.45 & 104.93 & 0.144 & 0.375 & -0.007 & -2 & 0.303 \\
JUNE & 44422.10 & 135.79 & -0.456 & 0.110 & -0.115 & -2 & 0.800 \\
CLARA & 27656.86 & 119.95 & -2.566 & -0.066 & -0.656 & 1 & 0.347 \\
\hline
\end{tabular}

Table 6. Diagnostic Checking of Rainfall-Runoff Model Unit Hydrograph Associated with Kalman Filter

\begin{tabular}{lrrrrrrr}
\hline typhoon & \multicolumn{1}{c}{ MSE } & MAD & MRE & VER & PVE & PTE & CE \\
\hline ORA & 43720.00 & 133.82 & -1.274 & -0.254 & -0.032 & -2 & 0.724 \\
PERCY & 2987.75 & 46.42 & -0.656 & -0.170 & 0.004 & -1 & 0.897 \\
JUNE & 20509.80 & 58.93 & -0.240 & 0.065 & -0.096 & -1 & 0.907 \\
CLARA & 3849.25 & 35.32 & -2.293 & -0.039 & -0.028 & -1 & 0.909 \\
\hline
\end{tabular}

MSE: Mean Square Error MRE: Mean Relative Error

PVE: Peak Value Error

CE: Coefficient of Efficiency
MAD: Mean Absolute Deviation

VER: Volume ERror

PTE: Peak Time Error 
inappropriate.

\section{CONCLUDING REMARKS}

Approaching flood can be likened to a nearing missile, and flood routing is regarded as to settle an antimissile system. In practical use, the applications of the Kalman filter to hydrologic models are not appropriate. The Kalman filter fails to give totally satisfactory predictions in the hydrologic routing by the fact that any specific objective (peakflow) cannot be designated in advance, as compared to the control system design. Without predetermined objectives, the predicted flows cannot seize the real values but chase the traces of the actual hydrograph.

\section{REFERENCES}

1. Bozic, S.M. (1979), Digital and Kalman Filtering, Edward Arnold.

2. Chiu, G.L., ed. (1978), “Applications of Kalman Filter to Hydrology, Hydraulics, and Water Resources," Proceedings of AGU Chapman Conference held at Univ. of Pittsburg, Pa.

3. Fagin, S.L. (1964), "Recursive Linear Regression Theory, Optimal Filter Theory, and Error Analysis of Optimal Systems," IEEE Intern. Conv. Record 12, pp. 216-240.

4. Gelb, A. ed. (1974), Applied Optimal Estimations, MIT Press, Cambridge, Mass.

5. Heffes, H. (1966), "The Effect of Erroneous Models on the Kalman Filter Response," IEEE Trans. Automatic Control 11, pp. 541-543.
6. Hino, M. (1973), "On Line Prediction of Hydrologic System,” Proc. XVth Conference IAHR, Istambul, pp. 121-129.

7. Jazwinski, A.H. (1970), Stochastic Processes and Filtering Theory, Academic Press.

8. Kalman, R.E. (1960), “A New Approach to Linear Filtering and Prediction Problems," ASME, J. Basic Eng. 82D, pp.35-45.

9. Wang, G.T., Yu, Y.S. and Wu, K. (1987), "Improved Flood Routing by ARMA Modelling and the Kalman Filter technique," J. Hydrol., 93, pp. 175-190.

10. Wood, E.F., ed. (1980), "Real-Time Forecasting/Control of Water Resource Systems," IIASA Proceedings Series, 8., Laxenburg.

\section{卡門濾波理論適用於水文演算否？}

$$
\text { 黄 文 政 }
$$

國立台灣海洋大學河海工程研究所

$$
\text { 摘 要 }
$$

洪水運動可比喻爲飛彈來襲, 而洪水演算則類 似於從事飛彈攔截演算。本文利用自由落體運動及水 文單位歷線例子, 説明卡門滤波理論並不適用於水文 演算, 主要原因爲水文演算時並無預先鎖定的目標 (洪峰) 存在。故預测時並無法捉到噵值, 而只是跟 在實際歷線後頭而已。 